\title{
Nuestro padre
}

\author{
FELIPE Y EDUARDO LÓPEZ-ARANGUREN
}

Los hijos e hijas de Aranguren, durante nucstra niñez y adolescencia, veíamos a nuestro padre como un hombre muy serio y estudioso, recluido en la zona del piso de Velázquez 25 que formaban su despacho y biblioteca, con escasas necesidades que nuestra madre se encargaba concienzuda y puntualmente de que estuvieran satisfechas. Nuestro padre era entonces, todavía, una persona privada, desconocida fuera de reducidos ámbitos intelectuales. Pero, casi exclusivamente dedicado al estudio y la reflexión, no era una persona familiar, es decir, un padre que tuviera una relación estrecha con sus hijos e hijas.

A partir del momento en que obtuvo la cátedra de Ética y Sociología de la Universidad de Madrid (1955), sus hijos e hijas constatamos cómo Aranguren se convirtió poco a poco en una persona pública, proceso que se aceleró después de su expulsión de la Universidad en 1965. Esta creciente dimensión pública situó a nuestro padre mucho más en el exterior que en el interior de la familia. Sus intereses principales estaban fuera del ámbito familiar, y era en el entorno de amigos, colegas y discípulos, mucho más que en el entorno familiar, donde nuestro padre se volcaba y daba de sí mismo.

Ha sido en los últimos años, tras la muerte de nuestra madre en 1990, cuando nuestro padre ha intentado recomponer el vínculo afectivo, no sólo con sus hijos $\mathrm{c}$ hijas, sino también con otros miembros de la familia. Un detalle al tiempo simbólico y funcional: a la muerte de nuestra madre cogió su agenda y copió cuidadosamente en la suya todas las anotaciones relativas a santos, cumpleaños y otros aniversarios importantes de hijos, hijas, nietos, nietas y otros familiares, de manera que pudiera expresar su cariño haciendo una llamada telefónica en la fecha apropiada. Podríamos decir, pues, que en los últimos cinco o seis años se restableció en verdad el vínculo afectivo, que le quisimos, que nos quiso, y que estamos en paz.

Creemos que debemos destacar, en este tema del cariño familiar y de la demostración de ese cariño, la muy estrecha relación que nuestro padre mantuvo con su hijo Alfonso, relación en la que posiblemente nuestro padre se apoyara para la recomposición del vínculo afectivo de que escribíamos más arriba. Alfonso era un chico aquejado del síndrome de Down que sufrió, además, durante la mayor parte de su corta vida (1956-78), de un serio problema de desviación de columna vertebral que le obligó a llevar durante años un incómodo corsé de acero y cuero, de las caderas al cuello, para intentar corregir tal defecto.

Nuestro padre hablaba del «misterio del ser humano» sin duda influido por Alfonso, del misterio del ser donde no hay ideas organizadas, donde no hay una respuesta «intelectual». Con nuestro hermano sólo se podía tener 
un tipo de relación, la afectiva, y lo más importante para él eran los amigos. «ढ̈Amigos?", te preguntaba, para a continuación darte la mano o un beso, según de quién se tratara. Pues bien, nuestro padre y Alfonso pasaron mucho tiempo juntos. Todos recordamos cómo, en el piso de Velázquez, Alfonso jugaba en el despacho con lo que ambos llamaban los «macacos» (unos muñequitos de plástico cuyo número aumentaba con regalos de unos y de otros) durante lo que parecian horas, mientras nuestro padre leía o escribía. También recordamos sus, en cierto modo, admirables juegos de pimpón en la dehesa El Cerezo, en Ávila. En el chalet de Aravaca padre e hijo compartieron habitación, y después de la muerte de Alfonso nuestro padre mantuvo la habitación como había estado, con los objetos y recuerdos de Alfonso en el mismo lugar. Creemos que fue esta relación con Alfonso la que permitió a nuestro padre, hombre más bien seco y parco en demostraciones afectivas, reconstruir la afectividad en la familia una vez desaparecida nuestra madre.

Mucho se ha escrito de las diversas etapas de Aranguren. Probablemente, de la época de nuestro padre de la que menos se sabe es el período de la guerra civil, pues sólo en los últimos años y en muy contadas ocasiones ha recordado nuestro padre sus sentimientos y experiencias en tales difíciles años. Ha contado que precisamente el día 18 de julio, y sin saber nada de lo que estaba ocurriendo, él, su padre y su hermano Eduardo viajaron cn automóvil de Madrid a San Sebastián para iniciar el veraneo. Ha contado también que, cuando la entrada en San Sebastián de las tropas franquistas era inminente, rechazó la sugerencia de su padre de marchar a Francia, prefiriendo quedarse en San Sebastián, no sólo con su padre, sino también con su novia, con quien se casaría en febrero de 1938, y la familia de ésta. Nuestro tío Eduardo se unió a los Requetés en cuanto pudo, nuestro padre fue movilizado y, a petición propia, enviado al frente de Aragón. No hay duda, sin embargo, de que carecía de la consistencia necesaria para ser un soldado, es decir, alguien que dispara contra otros seres humanos. Sus nervios, su estómago, cedieron, cayó enfermo, fue enviado al hospital de Zaragoza y posteriormente al hospital de Lujua (o Loiu), cerca de Bilbao. Allá fue su novia (nuestra madre) a buscarle una vez que nuestro abuelo Isidoro consiguiera la autorización militar para su vuelta a San Sebastián.

Terminada su corta experiencia como soldado, nuestro padre vivió el resto de la guerra civil, como él mismo ha dicho, en una especie de «exilio interior» y "retiro espiritual» durante los cuales se desarrollaron sus inquietudes filosóficas y, lo que es más importante, emergieron con gran intensidad sus preocupaciones religiosas y su interés en la mística, ligada a lecturas como los poemas de San Juan de la Cruz. Creemos que estas experiencias durante los años de la guerra civil le hicieron tomar una nueva dirección que marcaría su vida definitivamente.

En lo que a nosotros, sus hijos e hijas, se refiere, su religiosidad se manifestó en que todos fuimos enviados a colegios religiosos de pago en los que nos 
confirmaron e hicimos la primera comunión. En casa no hubo religión rutinaria o cotidiana: nunca se rezó el rosario, por ejemplo, ni se agradecían los alimentos antes de las comidas. Pero los más dóciles de los mayores hemos ido con nuestro padre a misa los domingos, misa que hemos seguido en gruesos misales de tapas negras y letra pequeña que él nos había regalado, hemos recorrido con él el día de Jueves Santo los siete monumentos de rigor, y hemos hecho alguna vez aquellos terroríficos «ejercicios espirituales» que el colegio organizaba.

Una etapa de nuestro padre que no sólo pudimos presenciar, sino presenciar como espectadores privilegiados, desde una cierta distancia, puesto que ya no viviamos en la casa familiar, fue su cambio, su rejuvenecimiento tanto externo cono interno, desde su contratación como profesor permanente por la Universidad de California en Santa Bárbara a partir de 1968-69. El profesor encorbatado, calvo y sobriamente vestido volvía con melena, grandes patillas, despechugado y con un aire escasamente profesoral. Nuestra madre, siempre conservadoramente elegante, le reprochaba su nuevo estilo de comportamiento, algunos de los términos o palabras que empleaba y, particularmente, su forma de vestir. La inmersión de nuestro padre en los últimos años sesenta y primera mitad de los setenta en la cambiante cultura universitaria californiana nos devolvió un padre y un profesor "al día», joven en su planteamientos e idcológicamente avanzado. Allí conoció y trató a Marcuse, de quien él, poco proclive a elogios, hablaba con admiración, al tiempo que sugería que se trataba de una admiración correspondida («venía a mis cursos de doctorado siempre que podía», le hemos oído decir). Y la experiencia californiana le llevó a intercsarsc por otros campos del conocimiento más sociológicos que filosóficos, como el erotismo, la comunicación y las actitudes y comportamientos políticos.

Los hijos e hijas hemos podido comprobar que la transformación y evolución de nuestro padre aumentó las diferencias entre él y nuestra madre. Aunque conviviendo bajo el mismo techo, sus vidas se hicieron divergentes. Y mientras que la vida de nuestro padre después de su jubilación continuó siendo una vida gratificante, plena de realizaciones y satisfacciones, la verdad es que los años de mayor de nuestra madre, en Aravaca y fallecido Alfonso, no fueron años felices. Todos lo sabemos y todos sentimos por ello un hondo pesar. Quizá esta divergencia, este distanciamiento, explique el hecho de que en familia nuestro padre continuara siendo un hombre introvertido, silencioso, poco comunicativo.

Nuestro padre mantuvo toda su vida dos elementos que probablemente provienen de su formación con los jesuitas: una manera de estoicismo, un autodominio que podríamos denominar «voluntad», y el examen de conciencia, que podríamos llamar «autocrítica». A ello unía un lenguaje claro, una idea de compromiso que para él presuponía la independencia, y una crítica permanente apoyada en el "talante» como estado de ánimo, como estilo de vida y como sentido de la vida. Esto le llevaba a una idea de servicio a la comunidad 
que se basaba en su «soledad solidaria» y se manifestaba en su gran accesibilidad y disponibilidad. A todo ello añadía la disolución del intelectual individual en el intelectual colectivo y su insistencia en que prefería ser recordado por las obras de aquellos que habían trabajado con y junto a él (lo que otros llamarían discípulos) que por su propia obra.

Los últimos meses de vida de nuestro padre nos han servido a todos para tener una idea más completa y perfecta de la vejez, para ser más comprensivos con las personas mayores, y para aprender a tratar con cariño a los seres amados que mueren. Aunque la disminución de facultades era ya notable en el momento en que se le anunció la concesión del Premio Príncipe de Asturias de Comunicación y Humanidades de 1995, es a partir de la entrega de este premio en noviembre de ese año cuando el deterioro físico le obligó a permanecer todo el tiempo en su casa de Aravaca. Sabiendo que la muerte venía, él mismo dijo una frase estremecedora: «Parece mentira, me estoy muriendo y no me duele nada.» Una frase entre el estupor y el agradecimiento, lo que no le impidió mantener su carácter fuerte hasta el último momento, renegando frecuentemente de médicos, enfermeras, amigos y familiares - un hatajo de «ignorantes», «pesados», «torpes» y «majaderos»—, de cualquiera que quisiera establecer un orden en su enfermedad. Hasta el último momento se negó a ser ordenado y dirigido, pese a saber que el cuerpo se rebelaba contra sus deseos de vivir, que el cuerpo se le moría.

El balance de su vida intelectual no es de nuestra incumbencia en este corto artículo. Sí querríamos insitir en que nuestro padre fue lo que quiso ser, un intelectual, es decir, y para utilizar sus propias palabras, «un excomulgado por sí mismo del sistema establecido y [que] se sitúa críticamente ante él», con una misión completa que en su componente moral consiste en «ayudar a construir o reconstruir la conciencia moral de la sociedad». Y nos gustaría, para terminar, rescatar la imagen de lo que también fue nuestro padre: un hombre enamorado de la vida, al que gustaba estar rodeado de amigos, interesado por la música y a quien le encantaba bailar, el cine y el teatro, el arte y la poesía, las mujeres, los viajes y el whisky de malta. 